\title{
A memória que resiste: o caminho da pesquisa com uma comunidade remanescente de quilombo
}

\author{
The memory that resists: the search path with a remaining \\ quilombo community
}

\section{La memoria que resiste: el camino de la investigación con una comunidad remanente de quilombo}

\author{
Lilian Maria Santos ${ }^{1}$ \\ Andréa Maria Narciso Rocha de Paula²
}

${ }^{1}$ Doutoranda do Programa de Pós-Graduação em Desenvolvimento Social (PPGDS) da Universidade Estadual de Montes Claros (Unimontes), sendo a área de concentração o Desenvolvimento Social e a linha de pesquisa "Movimentos Sociais, Identidades e Territorialidades". E-mail: lilianmsantos@yahoo.com.br, Orcid: http://orcid.org/0000-0001-5360-8739

${ }^{2}$ Doutora em Geografia - Programa de Pós-Graduação em Geografia (PPGEO), Universidade Federal de Uberlândia (UFU). Docente no Programa de PósGraduação- Mestrado e Doutorado em Desenvolvimento Social (PPGDS/ UNIMONTES). Professora no Departamento de Política e Ciências SociaisUnimontes. Docente no Programa de Pós-Graduação Sociedade, Ambiente e

Território-UFMG/UNIMONTES. E-mail: andreapirapora@yahoo.com.br, Orcid: http://orcid.org/0000-0003-2586-4043 
Resumo: O texto é um relato de experiência de pesquisa de doutorado em Desenvolvimento Social, cujo tema central é a memória enquanto constituinte no processo de afirmação identitária na reivindicação territorial de comunidades remanescentes de quilombo. 0 relato tem como objetivo apresentar uma discussão teórica sobre a categoria memória a partir de Bergson e Halbwachs, bem como descrever o caminho metodológico percorrido no estudo e a contribuição destes autores para o desenvolvimento da pesquisa. Em Bergson, a memória se destaca no seu caráter individual e subjetivo, fazendo o movimento do espírito para a matéria e para a ação no mundo, enquanto Halbwachs traz a dimensão das condicionantes sociais para o fenômeno da memória coletiva. Foi possível considerar que as teorias destes autores contribuem para o embasamento de pesquisas etnográficas que buscam apreender o fenômeno da memória, no que tange os processos de afirmação identitária na reivindicação territorial.

Palavras-chave: memória; reivindicação territorial; pesquisa etnográfica.

\begin{abstract}
The text is an experience report to doctoral research in Social Development, whose central theme is the memory as a constituent in the process of identity affirmation in the territorial claim of remaining quilombo communities. The report aims to present a theoretical discussion about the memory category from Bergson and Halbwachs, as well as to describe the methodological path covered in the study and the contribution of these authors to the development of the research. In Bergson, memory stands out in its individual and subjective character, making the movement of the spirit into matter and action in the world, whereas Halbwachs brings the dimension of the social determinants to the phenomenon of collective memory. It was possible to consider that the theories of these authors contribute to the foundation of ethnographic research that seek to apprehend the phenomenon of memory, regarding the processes of identity affirmation in the territorial claim.
\end{abstract}

Keywords: memory; territorial claim; ethnographic research.

Resumen: El texto es un relato de experiencia de investigación de doctorado en Desarrollo Social, cuyo tema central es la memoria como constituyente en el proceso de afirmación identitaria en la reivindicación territorial de comunidades remanentes de quilombo. El relato tiene como objetivo presentar una discusión teórica sobre la categoría memoria a partir de Bergson y Halbwachs, así como describir el camino metodológico recorrido en el estudio y la contribución de estos autores para el desarrollo de la investigación. En Bergson, la memoria se destaca en su carácter individual y subjetivo, haciendo el movimiento del espíritu hacia la materia y hacia la acción en el mundo, mientras que Halbwachs trae la dimensión de las condicionantes sociales para el fenómeno de la memoria colectiva. Es posible considerar que las teorías de estos autores contribuyen al embasamiento de investigaciones etnográficas que buscan aprehender el fenómeno de la memoria, en lo que se refiere a los procesos de afirmación identitaria en la reivindicación territorial.

Palabras clave: memoria; reivindicación territorial; investigación etnográfica. 


\section{INTRODUÇÃO}

Este relato de experiência foi construído com base na pesquisa de doutorado ${ }^{1}$ em Desenvolvimento Social, cujo tema central é a memória enquanto constituinte no processo de afirmação identitária na reivindicação territorial de comunidades remanescentes de quilombo, sendo que este texto tem como objetivo apresentar uma discussão teórica sobre a categoria memória a partir de Bergson e Halbwachs, bem como descrever o caminho metodológico percorrido no estudo e a contribuição destes autores para o desenvolvimento da pesquisa. Não nos dedicaremos aqui a discutir as categorias quilombo e território, pois o objetivo é esclarecer como a categoria memória pode contribuir para a compreensão e reflexão nos processos de luta e resistência pelo território tradicionalmente ocupado pelos povos e comunidades tradicionais.

A pesquisa acadêmica envolve escolhas no campo empírico e analítico, destarte transitamos na interdisciplinaridade do Desenvolvimento Social, pois o estudo dialoga com várias ciências sociais e humanas. A pesquisa contempla as questões de cunho social, cultural, econômico e político na análise de grupos submetidos a uma relação de poder e dominação no processo sócio-histórico de formação. Neste sentido, as comunidades quilombolas lutam pelo direito de produção e reprodução dos modos de vida, em que a terra ocupa dimensão afetiva em suas vidas, abrangendo outro modo de desenvolvimento que tensiona com as formas de organização do grande capital, pois se arranjam a partir de um modo singular de ser, de viver e se desenvolver. Nesta direção, a investigação trabalhada no processo de doutoramento centra-se nos fenômenos que envolvem memória, tradicionalidade e territorialização das comunidades, sendo que o interesse da pesquisa paira nos modos de vida cotidianos, as relações entre os indivíduos, a intersubjetividade, as construções e invenções que partem das práticas e das lutas do dia a dia do grupo, como reivindicam a ancestralidade, como o território é trabalhado e culturalmente construído.

\footnotetext{
${ }^{1}$ Doutorado em Desenvolvimento Social em curso, tendo início em março de 2016, com previsão de término em março de 2020.
} 
Com o intuito de compreender a memória coletiva que vem sendo acionada no processo de territorialização, ou seja, a memória como mediação no processo de territorialização, o que tem sido o foco do trabalho é como um grupo social que existia e resistia enquanto comunidade camponesa, residentes rurais, passa a territorializar enquanto um objeto jurídico específico. Portanto compomos o campo de estudo com a Comunidade Quilombola e Apanhadora de Flores de Raiz, localizada no Vale do Jequitinhonha, $\mathrm{MG}$, que se encontra em processo de luta pela retomada do território que foi expropriado pela ofensiva desenvolvimentista no Brasil.

A comunidade é formada por 25 famílias que habitam as casas que ficam todas em uma única rua muito comprida e, ao todo, são mais ou menos 96 pessoas residentes (incluindo todas as faixas etárias). Eles têm como principal ocupação a coleta de flores sempre viva, o artesanato do capim-dourado e as pequenas plantações. Alguns moradores trabalham na prefeitura de Presidente Kubitschek, município do qual a comunidade faz parte. Existe uma trajetória muito forte de garimpo na comunidade e em seu entorno, inclusive com toda a história de violência e exploração que perpassa o garimpo no Vale do Jequitinhonha. As lideranças principais da comunidadeque animam as lutas e organizam as atividades coletivas e de resistência - são compostas por mulheres jovens que dão continuidade à caminhada das suas mães e avós. É neste contexto que a comunidade luta pela titulação como Comunidade Remanescente de Quilombo e vive uma disputa pelo território com as fazendas de produção de eucalipto, que ocupam todo o seu entorno.

\section{APREENDENDO A MEMÓRIA}

Na construção do escopo da pesquisa, partimos do entendimento de que a memória deve ser compreendida principalmente a partir do diálogo com os velhos, os guardiões da memória, para assim entendermos como esta compõe a organização do grupo na dimensão da resistência. Desta forma, nas lembranças das pessoas idosas

[...] é possível verificar uma história social bem desenvolvida: elas já atravessaram um determinado tipo de sociedade, com características bem marcadas e conhecidas; elas já viveram quadros de referência familiar e cultural igualmente reconhecíveis: enfim, sua memória atual 
pode ser desenhada sobre um pano de fundo mais definido do que a memória de uma pessoa jovem, ou mesmo adulta, que, de algum modo, ainda está absorvida nas lutas e contradições de um presente que a solicita muito mais intensamente do que a uma pessoa de idade (BOSI, 2012, p. 60).

Concernente com Brandão (1998) em sua discussão sobre memória na obra "Memória Sertão", consideramos que tudo que eles (os mais velhos das comunidades) relatam que não é do presente, logo, é do passado. Deste modo, procedemos do entendimento de que todo o conteúdo narrado no pretérito é memória.

Neste sentido, compreendemos que discutir memória no campo interdisciplinar das ciências humanas e sociais requer a visita a dois autores de extrema relevância para o tema: Bergson e Halbwachs. E, ao realizar essa visitação teórica, percebemos que esses dois autores - o primeiro de base filosófica e o segundo, sociológica - acenam para caminhos não opostos, porém diferentes quando tratam da investigação sobre memória. Como a proposta da pesquisa é aprofundar nos estudos sobre a memória como constituinte de um processo que é coletivo, ou seja, a luta pelo território e pela produção e reprodução dos modos de vida, compreendida como um fenômeno social de grupo, precisamos dar conta das teorias que trazem a memória como fenômeno que se expressa tanto na condição individual como também na dimensão social.

Bergson (2006) aborda sobre as percepções imediatas, ou seja, aquelas pautadas na experiência consciente subjetiva, tal como ocorre em um exato momento, e considera que existe uma relação direta das percepções imediatas com os acontecimentos do passado, em que este interfere nos processos atuais de representação. É através da memória que o passado e o corpo presente misturam-se e acabam por ocupar o espaço da consciência ou mesmo até a percepção do passado passa a substituir a do presente, "pois elas só se conservam para tornarem-se úteis: a todo instante completam a experiência presente enriquecendo-a com a experiência adquirida" (BERGSON, 2006, p. 69). Na perspectiva da ação, o grau de utilidade da lembrança faz com que ela se sobreponha aos objetos percebidos, assim, a memória deve ser compreendida no seu âmbito subjetivo e também ativo. 
Nossas percepções estão certamente impregnadas de lembranças, e inversamente uma lembrança [...] não se faz presente a não ser tomando emprestado o corpo de alguma percepção onde se insere. Estes dois atos, percepção e lembrança, penetram-se portanto sempre, trocam sempre algo de suas substâncias mediante um fenômeno de endosmose (BERGSON, 2006, p. 70).

O autor considera que as pessoas reproduzem os comportamentos que são do passado e deram certo, ou seja, a memória é uma reserva contínua e constante das experiências adquiridas que subsidiam as decisões dos sujeitos.

Para Bergson (2006), existe uma diferença entre matéria e memória, pois a memória propriamente dita é espiritual e é dela que vem a lembrança, que é o registro da memória da percepção. As lembranças não são coisas e armazenamos lembranças pelo hábito. Já o cérebro é matéria e é a partir dele que é possível a atualização da lembrança, ou seja, ele é um meio para a atualização. A memória e o cérebro têm naturezas diferentes, a primeira tem natureza espiritual, e o segundo, material.

Para Bergson (2006), a consciência é uma ligação do passado com o presente e com o futuro, sendo que é o passado, de certa forma, que alimenta a percepção do presente, o qual, ao mesmo tempo, ao ser percebido, já é passado e já prospecta um futuro. O passado é o presente porque é sua atualização, enquanto o presente é o que já foi no momento da percepção. Deste modo, passado e presente se tornam contemporâneos, diferenciando-se apenas em relação à natureza de cada um: espírito, matéria. Ele também apresenta concepções sobre o inconsciente, no qual todas as lembranças habitam, é o lugar onde conservamos todos os registros para além do que concebemos conscientemente, é onde todos os registros vivem antes de serem atualizados.

Bergson (2006) conceitua duas memórias: a memória hábito e a memória lembrança. A primeira podemos chamar aqui de automática, pois é essa memória que nos dá condição de aprender esportes, por exemplo, ou decorar conteúdos e atividades da vida cotidiana, é a memória que ordena nossa vida social.

Como todo exercício habitual do corpo, enfim, ela armazenou-se num mecanismo que estimula por inteiro um impulso inicial, num 
sistema fechado de movimentos automáticos que se sucedem na mesma ordem e ocupam o mesmo espaço (BERGSON, 2006, p. 86).

Já a memória lembrança é composta por tudo que é registrado pela consciência, com todos os seus tempos, datas, imagens, singularidades. A memória hábito se expressa na perspectiva motora do corpo, adquire-se pela repetição, é o registro de toda a vida passada para o uso da vida prática, ela é ação, é trazida de acordo com as situações a que o sujeito se depara na vida cotidiana. "Ela já não nos representa nosso passado, ela o encena; e, se ela merece ainda o nome de memória, já não é porque conserve imagens antigas, mas porque prolonga seu efeito útil até o momento presente" (BERGSON, 2006, p. 89).

Para Bergson (2006), no hábito você aprende e não existe mais estranhamento, pois tem já uma experiência. Na memória, nada se perde, cada instante do que já passou com cada um de nós é registrado simultaneamente à percepção. Assim, todo registro é conservado, fica "guardado" no inconsciente em sua forma chamada lembrança pura e, somente diante da necessidade do agir da vida prática, os conteúdos emergem. Uma situação de agora traz a lembrança do que está registrado e, por isso, torna-se atual, passando de lembrança pura para imagem-lembrança, que já é o estado da consciência, para favorecer o ser humano para agir na sua vida prática. No momento de lembrar, os mecanismos motores entram em ação porque, ao recordar-se de algo, existe a escolha daquilo que vai favorecer o sujeito para agir no mundo, ele vai fazer associações de continuidade e de semelhança para a resolutividade da vida cotidiana. Só é possível reconhecer, associar e dar continuidade porque existe a lembrança, porque a situação já vivida está registrada na memória.

A memória lembrança se organiza no tempo, nos lugares, é singular, opera nos sonhos e nos devaneios. Por uma questão de sobrevivência, é mais comum vir a nossa consciência as lembranças utilitárias. Ao nos distanciarmos das ações práticas, permitimos as lembranças inúteis, ou seja, sem a função de sobrevivência, surgindo, assim, os conteúdos criativos, a memória lembrança. Existe uma pressão do inconsciente para a atualização das lembranças e só é possível a criatividade porque as lembranças inúteis, dos conteúdos do passado, emergem. A lembrança da memória se conserva 
sempre, pois não é matéria, logo, não pode ser destruída, porém ela necessita do cérebro para a atualização. Se a pessoa existe, logo, ela percebe e registra. O que é estimulado é a memória do corpo para sobreviver, e não a memória que cria. As pessoas mais próximas do hábito só atualizam os registros voltados para a ação, pois a memória lembrança é sempre evocada quando as pessoas se permitem sonhar, abstrair e devanear.

Para evocar o passado em forma de imagem, é preciso poder abstrair-se da ação presente, é preciso saber dar valor ao inútil, é preciso querer sonhar [...]. Também o passado que remontamos desse modo é escorregadio, sempre a ponto de nos escapar, como se essa memória regressiva fosse contrariada pela outra memória, mais natural, cujo movimento para diante nos leva a agir e viver (BERGSON, 2006, p. 90).

Embora carreguemos conosco todo o nosso passado, somente uma parte se torna consciente, e é aquela que necessitamos para favorecer o nosso agir no mundo. Para entendermos melhor, quando começamos a nossa vida "humana", entramos em contato com vários objetos e situações, somos afetados por eles, registramos esses eventos, repetimos ações para a sobrevivência e para sobressairmos na vida prática, aprendemos, registramos. Em todas as situações, lançamos mão dos registros considerados úteis para a vida prática e também da memória lembrança - os devaneios, sonhos etc., ou seja, os registros inúteis e do âmbito da criação -, que são registrados e vão sempre constituindo o conteúdo da memória, oportunizando a distinção das coisas e das ações. O passado é enriquecido a todo momento, assim como a experiência vivida, do presente, é enriquecida por toda a experiência do passado. Matéria e memória são completamente diferentes, porém agem conjuntamente, o criar só é possível a partir da evocação da lembrança, e aí temos a capacidade de refletir e fazer escolhas.

Importante considerar que, para Bergson (2006), o presente é como se fosse uma linha que separa passado e futuro, pois ou estamos no devir, e assim o presente ainda não é, ou, quando já é, transformou-se em passado, fazendo com que toda percepção seja memória e todo o vivido e percebido seja passado.

Mas, se nunca percebemos outra coisa que não nosso passado imediato, se nossa consciência do presente é já memória, os dois 
termos que havíamos separado de início irão fundir-se intimamente. Considerando desse novo ponto de vista, com efeito, nosso corpo não é nada mais que a parte invariavelmente renascente de nossa representação, a parte sempre presente, ou melhor, aquela que acaba a todo momento de passar. Sendo ele próprio imagem, esse corpo não pode armazenar as imagens, já que faz parte das imagens; por isso é quimérica a tentativa de querer localizar as percepções passadas, ou mesmo presentes, no cérebro: elas não estão nele; é ele que está nelas (BERGSON, 2006, p. 177).

Embora a obra de Bergson faça toda uma discussão teórica sobre memória hábito e memória lembrança, ela também deixa claro que o que realmente existe é uma diferença na forma em que se operam estas duas memórias, uma para a ação e a outra para os sonhos, devaneios e criação. O autor busca clarificar sobre como podemos compreender o fenômeno memória, porém centra-se em esclarecer sobre a memória individual na sua dimensão subjetiva e singular, sem se manifestar sobre como esse fenômeno se daria na dimensão social, interpessoal. Bergson, na sua obra Matéria e Memória, não aponta nenhuma direção para inferirmos sobre uma compreensão de memória coletiva e menos ainda podemos dizer se, em algum momento, ele teve interesse por essa perspectiva do tema.

Em Bergson, a memória se destaca no seu caráter individual e subjetivo, fazendo o movimento do espírito para a matéria e para a ação no mundo; não é proposta ou abordada a memória como fenômeno social, e sim a preocupação em marcar o que é do campo material e imaterial. Deste modo, podemos dizer que trazer Halbwachs para as nossas reflexões sobre memória é tentar alcançar a dimensão das condicionantes sociais para o fenômeno da memória coletiva.

Quando expomos o objetivo da pesquisa de doutorado, deixamos claro que a construção criativa da memória que buscamos compreender não é de uma única pessoa ou da exclusividade de suas lembranças sobre sua vivência singular. O que queremos compreender é a construção criativa da memória enquanto memória acionada para uma luta que é coletiva. No âmbito da luta coletiva, a memória acionada de um velho deve estar afinada com as memórias de outros velhos para ter ressonância em toda uma coletividade, instrumentalizando, assim, o acionamento de um objeto 
jurídico. Com esta constatação, voltamos para o entendimento de que é preciso aprofundar-se nas teorias sobre a memória coletiva. Nesse sentido, buscamos nos apoiar em Maurice Halbwachs (1990), visto que ele pondera que a memória, embora seja um trabalho no campo cognitivo do sujeito, é sempre constituída em grupo. Os eventos de lembrança e esquecimento são processos coletivos que se compõem na dimensão dos afetos, na relação uns com os outros nos grupos sociais. Para o autor, a lembrança se estabelece na relação do sujeito com o mundo social.

Nesse processo de construção e reconstrução, Halbwachs (1990) infere que a memória é seletiva e passa por um processo de negociação, envolvendo a memória coletiva e a memória individual. É nesse jogo de lembrança/esquecimento de uma memória coletiva que as comunidades quilombolas ativam um modo de vida e uma organização social tradicional para trilhar um caminho político para o acionamento de um objeto jurídico.

Debruçamo-nos a compreender a memória enquanto constituinte no processo de afirmação identitária na reivindicação territorial, ou seja, estamos nos referindo a uma memória que é afetada pelos grupos sociais e que também afeta a coletividade, logo, precisamos entender sobre a constituição da memória não somente no âmbito individual, mas também como fenômeno social. Halbwachs avança no sentido de, em vez de estudar a memória em si, propor a investigação dos quadros sociais da memória. Para este autor, a memória não se reduz à relação corpo-espírito, e sim procede no campo das relações interpessoais e com todas as instituições as quais o sujeito está inserido. A memória não está puramente e plenamente conservada e não se delimita a emergir com a função útil para a vida prática, a lembrança é acionada no contexto social, pelas situações e pelos outros.

Para Halbwachs, não existe uma lembrança pura retida no inconsciente, pois a lembrança é construída a partir dos acontecimentos vivenciados e, quando a lembrança emerge, o que nos aparece não é a mesma imagem de quando vivenciamos especificamente o acontecimento, essa lembrança é transformada pela nossa vivência de lá (o acontecimento) até aqui (o lembrado). O autor aborda a importância da linguagem como instrumento socializador da memória, pois é ela que aproxima em um mesmo contexto 
social e histórico as imagens tanto da lembrança como do sonho e da vigília. Lembrar não é somente reviver, é também refazer.

Quando lembramos algo que vivenciamos, o conteúdo já nos aparece alterado por outras vivências grupais e pelo que também foi contado sobre as vivências por familiares, grupos, etc. "[...] a lembrança é em larga medida uma reconstrução do passado com a ajuda de dados emprestados do presente, e além disso, preparada por outras reconstruções feitas em épocas anteriores e de onde a imagem de outrora manifestou-se já bem alterada" (HALBWACHS, 1990, p. 71).

Para Halbwachs, a memória coletiva é inerente a nossa existência, já que, mesmo quando pensamos que estamos tendo uma lembrança individual, ela foi produzida em um contexto grupal, seja na escola, seja na família, no trabalho ou com os amigos. Na medida em que consideramos que somos produtos de um contexto social, fica mais claro entendermos que a lembrança também é construída a partir das experiências de grupo, ou seja, a recordação individual é apenas uma perspectiva sobre uma memória que é coletiva. "Mas nossas lembranças permanecem coletivas, e elas nos são lembradas pelos outros, mesmo que se trate de acontecimentos nos quais só nós estivemos envolvidos, e com objetos que só nós vimos. É porque, em realidade, nunca estamos sós" (HALBWACHS, 1990, p. 26).

Para o autor, fazer parte de um grupo faz com que as lembranças permaneçam de forma mais viva em nós, pois nos identificamos com o grupo e acabamos por confundir o nosso passado com o dele. As lembranças serão constantemente trazidas e reforçadas pelas e com as testemunhas. Os acontecimentos do passado não ficam em nós retidos como uma lembrança pura como considerou Bergson, à mercê de uma utilidade ou de um devaneio. $\mathrm{O}$ que temos são traços de acontecimentos que produzimos e compartilhamos em grupo e que serão, também, evocados a partir da vivência social.

Quando dizemos que um depoimento não nos lembrará nada se não permanecer em nosso espírito algum traço do acontecimento passado que se trata de evocar, não queremos dizer toda via que a lembrança ou que uma de suas partes devesse subsistir tal e qual em nós, mas somente que, desde o momento em que nós e as testemunhas fazíamos parte de um mesmo grupo e pensávamos em comum sob alguns aspectos, permanecemos em contato com esse grupo, e 
continuamos capazes de nos identificar com ele e de confundir nosso passado com o seu (HALBWACHS, 1990, p. 28).

As lembranças são construídas a partir da vivência no grupo, mas, quando nos distanciamos dele, temos dificuldade em recordar aquilo que se passou no grupo. As lembranças se tornam mais possíveis quando estamos novamente em contato com alguma testemunha daquele grupo e esses outros nos ajudam a evocar as recordações. Sempre recorreremos a um testemunho para reforçar ou complementar o que estamos rememorando, porém sempre recorreremos primeiramente ao nosso testemunho e, posteriormente ao dos outros. Essa relação do testemunho próprio e do outro deve ser compassada, pois eles fazem parte da mesma vivência grupal. Para Halbwachs (1990), a memória sempre se remete a uma interação social, mesmo quando parece puramente individual e, provavelmente, uma pessoa não terá recordações de vivências sociais com grupos dos quais não se identifica.

Para que nossa memória se auxilie com a dos outros, não basta que eles nos tragam seus depoimentos: é necessário ainda que ela não tenha cessado de concordar com suas memórias e que haja bastante pontos de contato entre uma e as outras para que a lembrança que nos recordam possa ser reconstruída sobre um fundamento comum. Não é suficiente reconstruir peça por peça a imagem de um acontecimento do passado para se obter uma lembrança. É necessário que esta reconstrução se opere a partir de dados ou de noções comuns que se encontram tanto no nosso espírito como no dos outros, porque elas passam incessantemente desses para aquele e reciprocamente, o que só é possível se fizeram e continuam a fazer parte de uma mesma sociedade. Somente assim podemos compreender que uma lembrança possa ser ao mesmo tempo reconhecida e reconstruída (HALBWACHS, 1990, p. 34).

Importante ressaltar que para o autor, mesmo que toda a memória do indivíduo dependa dos grupos como a família a igreja, o trabalho, a escola, etc. e acabe sendo uma combinação de todas essas memórias, estas têm uma evocação que é individual, o que acaba caracterizando cada indivíduo e o seu passado de forma particular.

Um homem, para evocar seu próprio passado, tem frequentemente necessidade de fazer apelo às lembranças dos outros. Ele se reporta 
a pontos de referência que existem fora dele, e que são fixados pela sociedade. Mas ainda, o funcionamento da memória individual não é possível sem esses instrumentos que são as palavras e as idéias, que o indivíduo não inventou e que emprestou de seu meio. Não é menos verdade que não nos lembramos senão do que vimos, fizemos, sentimos, pensamos num momento do tempo, isto é, que nossa memória não se confunde com a dos outros (HALBWACHS, 1990, p. 54).

Existe uma memória autobiográfica, que envolve os acontecimentos diretamente vivenciados por nós, e uma memória histórica, que remete a eventos que acompanhamos ou vivenciamos indiretamente, como eventos políticos, sendo que "a primeira se apoiaria na segunda. Mas a segunda seria, naturalmente, bem mais ampla do que a primeira" (HALBWACHS, 1990, p. 55). Entretanto a memória histórica não representa o nosso passado especificamente, apenas um resumo dele. Já a memória autobiográfica representa a densidade e continuidade da vivência passada. O autor também se refere às lembranças reconstruídas e às lembranças dissimuladas. A primeira ele esclarece que são aquelas que se compõem, recompõem-se e se misturam a reflexões pessoais, lembranças familiares e imagens variadas. A segunda é quando temos a lembrança de uma vivência, porém, baseados em histórias contadas pelos outros que a compartilharam, compomos novas perspectivas para a lembrança e, assim, elas se enriquecem.

Halbwachs (1990) chama atenção para o fato de os indivíduos lembrarem aquilo que faz parte do nosso "quadro social de memória", ou seja, o processo de lembrar e esquecer é regulado pelos quadros sociais de identificação, que guardam e atuam no curso da memória e determinam o processo de rememoração do indivíduo. Quanto mais uma pessoa é integrada e participante de um grupo, mais ela tem condições de rememorar as vivências do grupo e dela no grupo como também de alimentar as lembranças do próprio grupo. Importante ressaltar que a memória coletiva e a memória individual se alimentam, porém a recordação confirmada e rememorada não somente pela memória individual, mas também pela memória do grupo, torna-se mais "sólida".

Outra questão importante é sobre a memória e o tempo. Para Halbwachs (1990), a divisão do tempo, sua organização e duração fazem 
parte de uma convenção social, servem para o arranjo da sociedade e, embora exista uma cronologia dita científica, cada grupo conforma seu próprio tempo.

Não é menos verdade que, de um grupo a outro, as divisões do tempo que se harmonizam não são as mesmas e não tem nesse caso o mesmo sentido. Tudo se passa como se um mesmo pêndulo comunicasse seu movimento a todas as partes do corpo social, Porém, na realidade, não existe um único calendário, exterior aos grupos e ao qual eles se refeririam. Há tantos calendários quantas sociedades diferentes, já que as divisões do tempo se expressam tanto em termos religiosos (cada dia sendo consagrado a um santo), tanto em termos de negócios (dias de pagamento etc.). Pouco importa que aqui e ali se fale de dias, de meses, de anos. Um grupo não poderia se servir do calendário de um outro. Não é no campo religioso que vive o comerciante e que pode encontrar os pontos de referência (HALBWACHS, 1990, p. 114).

Deste modo, pensar a dimensão do tempo da memória só é possível no âmbito grupal. O tempo que remetemos à memória é o tempo do grupo em que estamos inseridos, ou de um grupo de outrora; não existe um tempo universal, mesmo que nos remetamos a uma ordenação horária e de datas disciplinares que se pretende universal, o tempo que tratamos na memória é o tempo de uma reconstrução ou rememoração que também se organiza nele, mas que, de forma contínua, mantém um passado dentro do presente. O passado se ressignifica quando a memória coletiva liga as vivências do passado aos seus valores e necessidades do presente. "[...] é percorrendo em pensamento o quadro do tempo que ali encontramos a imagem do acontecimento passado: porém, para isso, é preciso que o tempo seja capaz de enquadrar as lembranças" (HALBWACHS, 1990, p. 101).

Halbwachs também faz considerações em relação à memória e o espaço jurídico, em que faz referência ao direito de propriedade, tema caro para este estudo. Ele refere que historicamente a lógica jurídica, para definir esse direito, sempre se pautou na memória coletiva. Os grupos, remetendo-se às lembranças, podem depor sobre o que de mais antigo viram, sabem ou ouviram falar. Os documentos e as leis sobre a propriedade não são socialmente considerados somente pela existência material, existe sempre uma relação com pessoas ou grupos que têm ou tiveram 
uma relação com a propriedade. A memória coletiva acaba por conter a memória dos direitos.

Qualquer princípio que invoquemos para fundamentar o direito de propriedade, ele somente adquire algum valor se a memória coletiva intervir para garantir-Ihe a aplicação. Como se poderia saber, por exemplo, que fui o primeiro a ocupar certa parcela do solo, ou que arei a terra, ou que determinado bem é produto de meu trabalho, se não nos reportássemos a um estado de coisas antigo, e se não estivesse convencionado que a situação não mudaria e quem poderia opor o fato sobre o qual fundamento meus direitos às pretensões de outros, se o grupo não conservasse a lembrança dele? Porém, a memória que garante a permanência dessa situação apóia-se ela própria, sobre a permanência do espaço ou, pelo menos, sobre a permanência da atitude adotada pelo grupo frente a essa porção do espaço (HALBWACHS, 1990, p. 145).

Outro ponto relevante do nosso trabalho e abordado por Halbwachs é a relação do grupo com o lugar. Os lugares que ocupamos, como as casas em que moramos ou que as pessoas afetivamente próximas residiram, imprime uma marca em nós, como imprimimos nos lugares também. Há uma produção de sentidos que se constrói nessa relação e compõe nossa memória. "O lugar ocupado por um grupo não é como um quadro negro sobre o qual escrevemos, depois apagamos os números e figuras" (HALBWACHS, 1990, p. 133). Cada detalhe do lugar tem sentido específico para os membros do grupo, tem significado singular para aquele grupo que vai se diferenciar de qualquer outro grupo e que, certamente, ficará na memória.

Diante do exposto, a memória coletiva é muito relevante para o estudo que realizamos, pois é a memória construída, reconstruída e ressignificada nos grupos sociais, porém centramos na memória coletiva dos velhos. Halbwachs (1990) faz referência aos mais velhos e a importância destes que conseguem, no presente, reatar o passado ao futuro.

[...] a presença de um parente idoso está de algum modo impressa em tudo aquilo que nos revelou de um período e de uma sociedade antiga, que ela se destaca em nossa memória não como uma aparência física um pouco apagada, mas com o relevo e a cor de um personagem que está no centro de todo um quadro que o resume e o condensa (HALBWACHS, 1990, p. 66). 
O idoso acaba por representar toda uma época, as relações e os acontecimentos dela. E, segundo Bosi (2012), nesse momento da velhice o homem deixa de ser ativo e de ser o propulsor da vida para ter uma função muito específica, que é lembrar, ser a memória dos grupos dos quais participa. Nesta pesquisa, são os velhos das comunidades que procuramos para trazerem à tona a memória dos processos de afirmação identitária e reivindicação territorial. A proposta textual é de que os sujeitos falem por eles, oportunizando o protagonismo dos interlocutores, pois eles são os sujeitos de suas histórias.

Em um primeiro momento, quando tratamos da memória coletiva, lançamos mão muito mais de Halbwachs, mas, no decorrer do trabalho, a teoria de Bergson tem auxiliado para compreender os aspectos individuais contidos nas narrativas e a articulação dos fenômenos individuais e coletivos da memória.

\section{PERCORRENDO OS CAMINHOS DA MEMÓRIA NA COMUNIDADE QUILOMBOLA RAIZ}

De acordo com o exposto até aqui, o campo de estudo ficou constituído pela Comunidade Quilombola Raiz, na qual a empreitada inicial era identificar e, posteriormente, entrevistar os mais velhos. Embora sejam os mais velhos os interlocutores principais do estudo, aqueles que entendemos que trazem os conteúdos da memória e que os apresentam, permitindo uma reinvenção para a composição das lutas, muitas vezes outras possibilidades de interlocutores surgem acionadas por esta memória dos velhos.

As lideranças mais jovens sustentam os discursos de tradicionalidade e territorialização a partir daquilo que os mais velhos contam, porque ouviram falar ou porque vivenciaram. Essas narrativas são compostas de histórias do passado, lutas do presente e expectativas para o futuro, muitas vezes articulando a vivência com os mitos e com os ideais de luta. Na vivência cotidiana na comunidade, os mais jovens envolvem-se com os mais velhos na labuta da roça, da horta, da panha de flores, da cozinha, da lida com os bichos, acompanhando as narrativas que trazem as memórias e que compõem os modos de vida. Para Benjamin (1994), quando o narrador conta uma história, 
ela está carregada de suas próprias experiências e também daquelas que ele ouviu serem contadas, fundindo conteúdos e transformando em uma experiência que também afeta e modifica quem está escutando. “A narração, em seu aspecto sensível, não é de modo algum o produto exclusivo da voz. $\mathrm{Na}$ verdadeira narração, a mão intervém decisivamente, com seus gestos [...] que sustentam de cem maneiras o fluxo do que é dito" (BENJAMIN, 1994, p. 220-1).

No primeiro momento da pesquisa de campo, realizamos o pré-campo na Comunidade de Raiz, em que o objetivo foi conhecer um pouco a comunidade, fazer os primeiros contatos e organizar as idas, as pessoas que seriam entrevistadas e as atividades desenvolvidas. Esse momento foi muito importante, pois possibilitou a reflexão sobre como entrar na comunidade de forma menos invasiva possível, considerando que o pesquisador é um "de fora" e que sua chegada "para ficar" um período acaba por causar estranhamento e desconfianças, por isto tentamos construir uma chegada mais gradual, como aponta Brandão (2007, p. 13-4):

Eu acho que é muito enriquecedor viver um tempo, que, dependendo do tempo global que você tenha, pode ser um dia, dois, uma semana, até quinze dias, quem sabe até um mês de puro contato pessoal, se possível, até de uma afetiva intimidade com os bares, as ruas, as casas, as pessoas, os bichos, os rios [...] e assim por diante. Conviver, espreitar dentro daquele contexto o que eu chamaria o primeiro nível do sentir, sentir como é que o lugar é, como é que as pessoas são, como é que eu me deixo envolver. Isso é muito bom, porque faz com que a gente entre pela porta da frente e entre devagar.

A estadia durante dias seguidos na Comunidade Raiz permite o acompanhamento do cotidiano, oportunizando a aproximação dos fatos, conteúdos e questões para as elucubrações da pesquisa. Desde os primeiros contatos, temos acompanhado sistematicamente as atividades da comunidade referentes às estratégias de luta pelo território.

Essa aproximação permitiu perceber que a reinvenção da memória está presente na relação entre as pessoas, das pessoas com a natureza e na produção e reprodução do modo de vida da comunidade. O estar lá junto da comunidade propiciou aproximações com as categorias que dialogam com o acionamento da memória, pois Raiz é o lugar de onde partem muitas 
questões, mas também para onde levamos tantas outras que surgem nas pesquisas bibliográficas.

A perspectiva exclusivamente qualitativa da pesquisa possibilitou a aproximação da realidade social e cultural dos atores participantes, bem como permitiu a interação do pesquisador com os grupos sociais envolvidos e o conhecimento do mundo subjetivo desses grupos (DEMO, 2001; MINAYO, 2006). O esforço tem sido no sentido de desenvolver uma pesquisa na qual o pesquisador busca aproximar-se das vivências e das interpretações que os moradores da comunidade têm de seus modos de vida e dos processos de politização, reivindicação territorial e identitária.

Para tanto, fizemos a opção pela etnografia, pois entendemos que este é o caminho para estudar com profundidade como se processam as interações e ações na comunidade. É a etnografia que permite apreender a cultura deles, os modos de ser e de viver da comunidade em uma perspectiva densa, como acena Geertz (1978). Estamos enfrentando na prática de observação "uma multiplicidade de estruturas conceptuais complexas, muitas delas sobrepostas ou amarradas umas às outras, que são simultaneamente estranhas, irregulares e inexplícitas, e que ele [o etnógrafo] tem que, de alguma forma, primeiro apreender e depois apresentar" (GEERTZ1978, p. 20).

Como o propósito é participar do cotidiano da comunidade, conviver com os detalhes do dia a dia, utilizamos também como técnica de coleta de dados a observação participante, que consiste em observar, interagindo com a comunidade, fazendo parte de sua rotina, estabelecendo uma relação interpessoal com os participantes (BRANDÃO, 2007).

Para a utilização desta técnica, é preciso se atentar para alguns aspectos, como: o tempo de observação, que não pode ser curto, pois deve oportunizar a contaminação com o lugar e familiarização com o grupo social; o entendimento de que os fenômenos sociais são complexos e não são passíveis de controle; compreender que embora esteja inserido no grupo social o pesquisador não é um "nativo"; entender a necessidade de um informante-chave que também passa a ser um colaborador, pois passa a influenciar nas interpretações; perceber que também está sendo observado pelo grupo social; afinar os sentidos para a observação, escuta e interpretação; estar sempre presente no contexto do grupo social, mesmo que pareça 
repetitivo; reconhecer que o diário de campo é a tradução da vivência como pesquisador; entender que no campo estaremos sempre revendo, refletindo e reformulando a pesquisa; lembrar que ali está sendo estabelecida uma relação social que deve ser horizontal (BRANDÃO, 2007; FOOT-WHITE, 2006).

Na pesquisa de campo [...] o etnógrafo tem o dever e responsabilidade de estabelecer todas as leis e regularidades que regem a vida tribal, tudo que é permanente e fixo; apresentar a anatomia da cultura e descrever a constituição social. Mas estes elementos, apesar de cristalizados e permanentes, não se encontram formulados em lugar nenhum. Não há códigos de lei, escritos ou expressos explicitamente; toda a tradição tribal e sua estrutura social inteira estão incorporadas ao mais alusivo dos materiais: o próprio ser humano (MALINOWSKI, 1984, p. 24).

Para que a pesquisa alcance a profundidade pretendida no acesso à memória, como já relatamos, partimos do entendimento de que são as pessoas mais idosas da comunidade que poderão dizer sobre a história, as práticas e vivências da comunidade, sendo que, nestes conteúdos, poderemos encontrar as categorias que permitam compreender a memória enquanto constituinte no processo de afirmação identitária na reivindicação territorial. Neste caminho, Thompson (1998) considera que a construção de uma estratégia de coleta de dados via história tem nos informantes mais idosos uma perspectiva de registro vasto sobre a história de vida que reflete todo um contexto social e histórico.

Não estamos preocupados com uma cronologia das idéias sobre memória. Procuramos entender as condições, os modos de produção e as práticas que envolvem motivos e formas de lembrar e esquecer, maneiras de contar, de fazer e registrar histórias (SMOLKA, 2000, p. 168).

As entrevistas que realizamos são abertas e os temas também são desencadeados a partir da observação e convívio nas comunidades. Vale a pena ressaltar que o diário de campo, desde o primeiro contato com as comunidades, já faz parte do cotidiano desta pesquisa. Como orienta Brandão (2007), primeiro deve-se observar as pessoas das comunidades, suas atividades, relações e modos de agir no cotidiano e, posteriormente, avançar com as entrevistas mais especificamente. Todo o material de observação foi transcrito e, a partir dele, as primeiras possibilidades de articulação e compreensão foram elaboradas. Baseados neste conteúdo, trabalhamos 
em um "roteiro de entrevista", mas não para o aprisionamento, e sim para dar um norte, para dar indicações para as entrevistas, pois

[...] entra a questão de pedir às pessoas que reflitam sobre a sua prática, que interpretem aquilo que elas estão fazendo e que se interpretem através daquilo que estão fazendo. Isso que nós temos o costume de chamar de ideologia, ou seja, as categorias sociais, experiências de relações sociais que determinam e configuram práticas, a prática produtiva, a prática política, a prática ritual, a prática familiar, e assim por diante... as pessoas têm um pensar sobre isso. [...] uma outra forma de fazer isso [...] pedindo que as pessoas reconstruam uma história que toca isso. Pedir que as pessoas falem como eram, até onde a memória alcança, as relações da prática econômica do campesinato, como elas foram se modificando e como elas são agora (BRANDÃO, 2007, p. 16-7).

Conduzimos as entrevistas considerando que elas devem partir de falas espontâneas, das quais vão surgindo as perguntas e, a partir destas, as pessoas vão dizendo e apresentando as categorias que emergem de suas próprias narrativas. As entrevistas são gravadas e posteriormente transcritas, compondo o material de análise. O envolvimento e a participação no cotidiano das comunidades são uma construção que se faz junto, não tem nada pronto ou definido e preestabelecido. Importa dizer que a construção final de como se estruturará um campo de conhecimento, a partir do nosso estudo, vai se dar na articulação analítica das observações e entrevistas construídas na e com as comunidades.

Thompson (1998) ressalta a importância de buscarmos o maior número de informações, tanto teóricas como de fatos históricos sobre determinado tema que queremos conhecer, para que seja possível uma "preparação cuidadosa da forma das perguntas" (THOMPSON, 1998, p. 257). Esta preparação envolve, inclusive, colocar poucas perguntas, porém que deem conta de oportunizar que a entrevista flua. O autor ainda chama atenção para o roteiro de entrevista, o qual considera que deva servir apenas como uma orientação, pois deve-se considerar a flexibilidade, e também para o tom da entrevista, que quem deve dar é o informante. Assim, o roteiro de entrevista "é essencialmente um mapa para o entrevistador; pode-se recorrer a ele ocasionalmente, mas o melhor é tê-lo na cabeça, de modo que se possa percorrer o território com segurança" (THOMPSON, 1998, p. 263). 
As entrevistas foram trabalhadas de forma que pudessem proporcionar a emergência de conteúdos que abordassem: como os antepassados do interlocutor chegaram ali na comunidade, todo o percurso daqueles que chegaram primeiro, os costumes, as crenças, as festas, as práticas de trabalho, lazer, relação familiar, religiosidade, o que estava esquecido e o que deve ser lembrado, como se deu a organização e politização da comunidade e a relação da comunidade com o lugar.

$\mathrm{O}$ argumento em favor de uma entrevista completamente livre em seu fluir fica mais forte quando seu principal objetivo não é a busca de informações ou evidência que valham por si mesmas, mas sim fazer um registro "subjetivo" de como um homem, ou uma mulher, olha para trás e enxerga a própria vida, em sua totalidade, ou em uma de suas partes. Exatamente o modo como fala sobre ela, como a ordena, a que dá destaque, o que deixa de lado, as palavras que escolhe, é que são importantes para a compreensão de qualquer entrevista (THOMPSON, 1998, p. 258).

Até o momento deste artigo, várias entrevistas já foram realizadas com as pessoas mais velhas da Comunidade Raiz, as quais têm entre 63 e 84 anos e conhecem com profundidade a história da comunidade. Uma entrevista é um encontro entre duas pessoas e, muitas vezes, o que queremos compreender pode despertar memórias dolorosas que remetem a sentimentos profundos, inclusive de dor. Para este momento, foi muito importante o preparo para execução das abordagens com os interlocutores, que se deu através da proximidade e familiaridade com os entrevistados, quebrando resistências e criando um ambiente menos formal. Remontar a história de escravidão, de exclusão e de violência e perceber que essa condição não ficou no passado, mas que ainda se reproduz hoje, foi uma experiência muito forte para alguns entrevistados.

E consideramos pertinente trazer ainda uma outra dimensão a ser explorada: o discurso como (locus de?) memória. Estudos sobre memória têm nos mostrado que o discurso constitui lembranças e esquecimentos, que ele organiza e mesmo institui recordações, que ele se torna um locus da recordação partilhada - ao mesmo tempo para si e para o outro - locus portanto, das esferas pública e privada. Sob os mais diversos pontos de vista, a linguagem é vista como o pro- 
cesso mais fundamental na socialização da memória. A possibilidade de falar das experiências, de trabalhar as lembranças de uma forma discursiva, é também a possibilidade de dar às imagens e recordações embaçadas, confusas, dinâmicas, flúidas, fragmentadas, certa organização e estabilidade. Assim, a linguagem não é apenas instrumental na (re)construção das lembranças; ela é constitutiva da memória, em suas possibilidades e seus limites, em seus múltiplos sentidos, e é fundamental na construção da história (SMOLKA, 2000, 187).

No processo analítico da investigação de campo, além dos conteúdos das entrevistas realizadas, também têm feito parte da nossa análise oficinas e atividades de grupo que foram acompanhadas, como: oficinas desenvolvidas pelos projetos universitários e por ONGs; oficinas conduzidas pelas lideranças da comunidade; reuniões comunitárias; e ainda conversas informais e não gravadas com os idosos e outros comunitários.

Para compreensão das práticas de oficinas, nós nos orientamos pela concepção de Spink, Menegon e Medrado (2014, p. 33), que consideram que "as oficinas são configuradas como ferramentas ético-políticas privilegiadas", pois são espaços dialógicos de reflexão e produção de sentidos. Espaços estes que permitem que todas as versões emerjam, que as controvérsias apareçam, que aconteçam trocas simbólicas e coconstrução de possibilidades para o grupo, ou seja, têm caráter não somente de produção de informações para o pesquisador, mas são transformadores para o próprio grupo.

Nas oficinas que foram acompanhadas, a memória é sempre acionada como elemento central para o remonte da história do lugar, da cultura e tradição, com o intuito de produzir conteúdos que possam instrumentalizar discursos, estratégias e documentos para a luta pelo território e pelos direitos à produção e reprodução dos modos de vida.

Ressaltamos o potencial das oficinas em promover o exercício ético e político, pois, ao mesmo tempo em que geramos material para análises, criamos um espaço de trocas simbólicas que potencializam a discussão em grupo em relação à temática proposta, gerando conflitos construtivos com vistas ao engajamento político de transformação (SPINK; MENEGON; MEDRADO, 2014, p. 33).

O momento analítico desta pesquisa se configura quando iniciamos a fase de categorização e discussão de dados, quando começamos a trabalhar 
no sentido de compreender os fenômenos sociais. Este momento, para Brandão (2007), é quando eruditizamos a categoria deles, ou seja, quando nos deparamos com novas categorias e nos dedicamos a sistematizá-las, buscando encontrar os significados e analisá-los à luz das teorias. Neste contexto, Geertz (1978) chama atenção para a escrita dos textos de base etnográfica, pois "são eles mesmos interpretações e, na verdade, de segunda e terceira mão. (Por definição somente, somente um 'nativo' faz a interpretação em primeira mão: é a sua cultura)” (GEERTZ, 1978, p. 25). Para o autor, o que o pesquisador faz é uma ficção. Uma coisa é a cultura em si, vivenciada, localizada, outra coisa é a cultura eruditizada e expressa nos textos científicos. O que nós pesquisadores temos é a tradução dos modos de vida deles, ou seja, "um artifício erudito".

\section{CONSIDERAÇÕES FINAIS}

Podemos considerar que as abordagens explicativas da categoria memória, a partir de Bergson e Halbwacks, não fazem parte da mesma égide analítica, mas não são excludentes, pois o primeiro autor nos oferece a compreensão no campo individual, e o segundo, a dimensão social. Deste modo, podemos inferir que as teorias destes autores contribuem para o embasamento de pesquisas que buscam apreender o fenômeno da memória envolvido nos processos de afirmação identitária e lutas coletivas. O relato de experiência da pesquisa de doutorado possibilitou também apresentar o caminho metodológico desenvolvido no estudo, assim como a contribuição desses autores para a construção da investigação empírica.

\section{REFERÊNCIAS}

BENJAMIN, Walter. O narrador. Considerações sobre a obra de Nikolai Leskov. In: BENJAMIN, Walter. Magia e técnica, arte e política: ensaios sobre literatura e história da cultura. 7. ed. São Paulo: Brasiliense, 1994.

BERGSON, Henri. Matéria e memória: ensaio sobre a relação do corpo com o espírito. 3. ed. São Paulo: Martins Fontes, 2006.

BOSI, Ecléa. Memória e sociedade: lembranças de velhos. 17. ed. São Paulo: Companhia das Letras, 2012. 
BRANDÃO, Carlos Rodrigues. Reflexões sobre como fazer trabalho de campo. Revista Sociedade e Cultura, Goiânia, v. 10, n. 1, p. 11-27, jan./jun. 2007.

BRANDÃO, Carlos Rodrigues. Memória Sertão: cenários, cenas, pessoas e gestos nos sertões de João Guimarães Rosa e de Manuelzão. São Paulo: Cone Sul/UNIUBE, 1998.

DEMO, P. Pesquisa e informação qualitativa. 2. ed. Campinas, SP: Papirus, 2001.

FOOTE-WHITE, William. Sobre a evolução da sociedade de esquina - Anexo A. In: FOOTE-WHITE, William. Sociedade de esquina. Rio de Janeiro: Jorge Zahar, 2006. p. 283-363.

GEERTZ, Clifford. Uma descrição densa: por uma teoria interpretativa das culturas. In: GEERTZ, Clifford. A interpretação das culturas. Rio de Janeiro: Zahar, 1978. p. 13-41.

HALBWACHS, Marice. A memória coletiva. Tradução de Beatriz Sidou. São Paulo: Centauro, 1990.

MALINOWSKI, Bronislaw. Argonautas do Pacífico Ocidental: um relato do empreendimento e da aventura dos nativos nos arquipélagos da Nova Guiné melanésia. (1922). São Paulo: Abril Cultural, 1984.

MINAYO, Maria Cecília de Souza. O desafio do conhecimento: pesquisa qualitativa em saúde. 9. ed. São Paulo: Hucitec, 2006.

SMOLKA, Ana Luiza Bustamante. A memória em questão: uma perspectiva históricocultural. Educação \& Sociedade, Campinas, SP, ano XXI, n. 71, p. 166-93, jul. 2000. Disponível em: http://www.scielo.br/pdf/es/v21n71/a08v2171.pdf. Acesso em: abr. 2018.

SPINK, Mary Jane; MENEGON, Vera Mincoff; MEDRADO, Benedito. Oficinas como estratégia de pesquisa: articulações teórico-metodológicas e aplicações ético-políticas. Psicologia \& Sociedade, Belo Horizonte, v. 26, n. 1, p. 32-43. 2014. Disponível em: http://www.scielo.br/pdf/psoc/v26n1/05.pdf. Acesso em: maio 2018.

THOMPSON, Paul. A voz do passado - história oral. 2. ed. São Paulo: Paz e Terra, 1998. 